\title{
Denkwürdigkeiten
}

f ü $\mathbf{r}$

\section{die Kriegskunst}

\author{
end
}

\section{Kriegsgeschichte.}

$$
\begin{gathered}
\text { Herasgegeben } \\
\operatorname{ron}
\end{gathered}
$$

•inigen Officieren des Königl. Preufsischen Generalstabs.

$$
\begin{gathered}
Z \text { we } i t e s ~ \\
\text { (Miteinem Plan.) }
\end{gathered}
$$

$$
\text { B e r } 1 \text { i n } 18187 \text {, }
$$

in der healsshulbuchlatidlung. 
